\title{
Forensic Mark Examination of Vehicle Keys
}

\author{
ELEK Imre ${ }^{1}$
}

\begin{abstract}
The inspection of a key by an expert mark examiner covers evaluation of tech-nological traces, presumption of origin, falsification related mark examinations, search marks of duplicator and sampler equipment, as well as identification, rec-ognition of shape characteristics and therefore decoding. The author on the basis of his several decades of experience demonstrates that a vehicle key belonging to a car is the most important safeguarding gadget, what kind of marks it may bear, and how it could be read in the aspect of forensic tool mark examination.
\end{abstract}

Keywords: Forensic tool mark examination, key duplication, copy traces, individ- ual characteristic of tool marks

\section{Introduction}

In accordance with crimes against property it is often important to find out the way the loca- tion was approached and the method the lock was operated on by the perpetrator. In case of closed rooms or vehicles the mechanical lock or its assigned key may become a tool mark car- rier. Tool marks may also reflect the formative equipment on tool mark group and individual specialities level, but it may be practical to determine the forming mechanism as well. [1-7]

Lock examination is interconnected to key examination, which occasionally determines the result of lock examination, because it might be necessary to examine the adapted and used keys to clarify the circumstances of the illegal lock opening.

Of the above mentioned, key duplication and its circumstances are the focus of the fo- rensic key examination. This kind of key examination has importance when it is necessary to investigate and to verify widely the illegal lock operation, whether during the examined occurrence the perpetrator could have used a duplication of the key and the sampling source of this duplication could have been one of the keys in proper use. Typically these examina- tions are related to vehicle theft, therefore discussing certain issues of key examination is based on vehicle keys.

\section{Aims and Methods}

My intention in writing this essay was to demonstrate the mechanical key as the special car- rier of mark characteristics in the light of observations which were acquired during the daily routine examinations. To achieve my purpose I used my experiences from my daily profes- sional routine work, international bibliography, several examiner tools and microscopes. Be- cause of the identification of manufacturer marks, manufacturing trace particularities, during the forensic examination of the key, reference samples and databases from manufacturers are

1 Senior Mark Examiner, Trace Expert Laboratory, Department of Forensic Experts, Hungarian Institute for

Forensic Science; e-mail: eleki@ orfk.police.hu 
required. With the complex examination of the key, there might be a possibility for answering the following questions:

- How many keys were adapted to the original set and what kind of functions did these have?

- Were the mechanical code of the examined keys the same?

- Are the keys' mechanical codes equal to the manufacturer's adapted mechanical codes?

- Are these keys original, duplicated or from the aftermarket?

- Could be the damaged mechanical code of the grooves be reconstructed?

- How did the damage of the keys issue?

- What level of the keys' usage shabbiness can be determined and is this in accordance with the usage period of the key? (In case of vehicle keys it may pertain to usage peri- od, mileage and lifetime.)

- Is it possible to detect a duplicator sampling on the keys' milling, if yes, when could it happen during the key usage or rather the vehicle usage period?

- Are the manufacturer notations (profile code, transponder code, logo, and other nota- tions) original or have they been changed?

\section{Results and Discussion}

\section{Key Types and Development of Mechanical Code Systems}

The appearance and the mechanical code of the keys are changing constantly. The change is caused by various effects such as technological progression, security aspects, changing of standard settings, enhancement of user comfort, optimizing protection against environmental effects, improvements in function safety or rather other manufacturer considerations. There were multiple generational changes in the past 30 years, for instance in the automotive in- dustry and the development of vehicle locks' mechanical codes. The sprung-pin system locks were replaced by the wafer-pin system, a central lock was introduced, within the wafer-pin system symmetric milling was formed, beside the traditional milling the inner course keys appeared, in addition to this systems well known simple-, double- and four-course. With the headway of smart systems the mechanical key's practical function has lost significance, one after the other keys appear with hidden mechanical milling.

\section{Key Duplication and Key Producing Technologies}

Of the known crimes to mark examiner experts there are many types of key duplicating and key making: such as making a cast, taking a photo, making a key for a disassembled lock, key making by impression method, handcrafting a key by knowing the milling code or making it with special cutting dies, and duplicating the key by a key duplicator machine with a sample key. Regarding the formation of marks, the key duplicator machines are basically divisible into two groups.

There is the non-capable key duplicator and key making machines for sample key mount- ing. These machines - in view of the milling code - work with the proper set of indentation depth and with linear stepping. Thus functioning equipment have no importance in the aspect of the duplicative key, since that key is out of touch along the equipment. 
There is the equipment which clamps the duplicative key in a special clutch and scans the milling mechanically for instance with a depth guide or tongue. These key duplicator ma- chines have particular features, and after duplication the copy traces are well demonstrable. There are several systems in the scanning method of those key duplicator machines which are capable to cramp the duplicative key. Naturally, the condition of tool marks to be formed is the physical connection, thus in case of key duplicator machine types which optically detect the milling shape (e.g. with laser scanning) the marks of scanning are not identifiable.

There are other methods for getting the key profile and the information about the lock's mechanical combination, such as taking a photo, scanning or drawing. In virtue of visual information the milling and cutting code can be identified of the given key, and a proper key can be made. Aside from several vehicle types, this mechanical code information means

6-10 slides or rather pin positions with 4-6 different levels. On the basis of this information almost any mechanical key can be made, even in the case of keys with several mechanical code variations.

From the viewpoint of forensic mark examination the used duplicative sample might have significance, when mechanical connection is established between the milling machine and the key during the duplication sampling process.

Key duplicator machines with a mechanical scanner leave dynamic marks during the scanning process, but on occasion static mark components may be left as well. In each case, during the clamping process static marks are formed, and the dimension may vary depending on the quality of the material, on coating and on the gauge of the coupling force. [8] [9] [10]

\section{The Presumption of the Keys'Ancestry and Origin, Possibilities of Identifying Duplicator Machines}

It is significant to the manufactured original set of keys, especially in case of vehicle keys, that each element of the set was made with the same machine during the same process. Similar conditions during different manufacturing periods lead to similar surface and form characteristics. These, on group-characteristic level, eventually may manifest in individual speciality. Regarding the nature of the technological process it is possible to draw conclu- sions about group specialities or individual peculiarities. For example on the successively formed grooves the structure image of the mark gouge will be similar as well. This is verified by the numerous observations in the course of key examinations.

On the level of individual speciality it is also possible to examine the technological marks, rarely in case of dynamic marks made by milling, but in case of clamping, stamping and cut- ting tools the individual character is more likely to be formed. (Figure 1) 


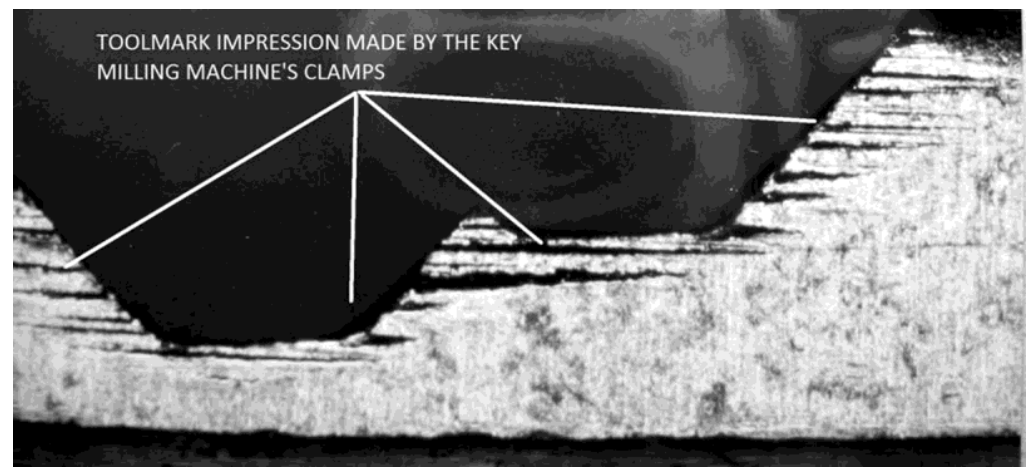

Figure 1. Static tool mark of a vehicle key-bit cutter. (Source: own snapshot)

\section{Specialities of Marks Left by the Key Duplicator Machine's Clamps}

On the key that is used for sampling, in each case the mark on the keys' bit or on the sides of the cuts is made by opposite acting surfaces, which is worked out in the form of a static mark (dent). As the cramping of the key to be copied requires accurate settings, the marks are also generated regularly (e.g. the mark runs straightaway with the fore-axis). The dimension and perceptibility of the mark substantially depends on the stock of the cramped key (in case of soft stock keys the dent is bigger), on the torque and shaping of the cramping tool (e.g. with the same settings a flat surface cramping tool leaves smaller mark than a corded one). In sev- eral cases the mark of the cramping tool is not generated adequately to make it possible to be examined. The surface of the cramping tools is worn out and damaged in time during usage, and these changes are imaged on the surface of the dents. These may be evaluated as the in- dividual characteristic of the mark, which may have significance during a later investigation.

By the combined examination of the general shabbiness and over-shabbiness of the mark it is ascertainable what kind of scale of shabbiness during and after clamping was formed on the key. Date-like time of the mark's formation cannot be determined, but the background information of the key's usage is possible to conclude; which part of the determined period the mark on the key was formed, for example:

- The mark was formed in the original state of the key and after the formation of the mark the key was in use for a longer period. In this case the time of formation of the mark is closer to the beginning of the given period.

- The mark was formed in the moderately worn-out state of the key and after its forma- tion the key was in use for a longer period. This statement refers to the formation time of the inspected mark is estimated at the middle of the key's usage period.

- The mark was formed in the firmly worn-out state of the key and after its formation the key was in use only a little. This statement refers to the formation time of the inspected mark is estimated at the middle of the key's usage period.

\section{Characteristics of Marks Left by Depth Guide}

On the grooves of classic cylinder lock keys (in case of symmetric grooves usually on one side of the blade) the depth guide leaves a regularly located dynamic mark through on a 
positionally fixed key. As long as the scanner tongue is in good condition, thus its surface is undamaged, the working interface is sharp, in this case a husker type, parallel, groove struc- tured dynamic mark comes about. Occasionally by such marks, microscopic scale scissels, ram and deformative effects are discoverable. The depth guide may cause secondary changes during the duplicating sampling process, such as positive and negative deformation of the milling cross-section profile. (Figure 2)

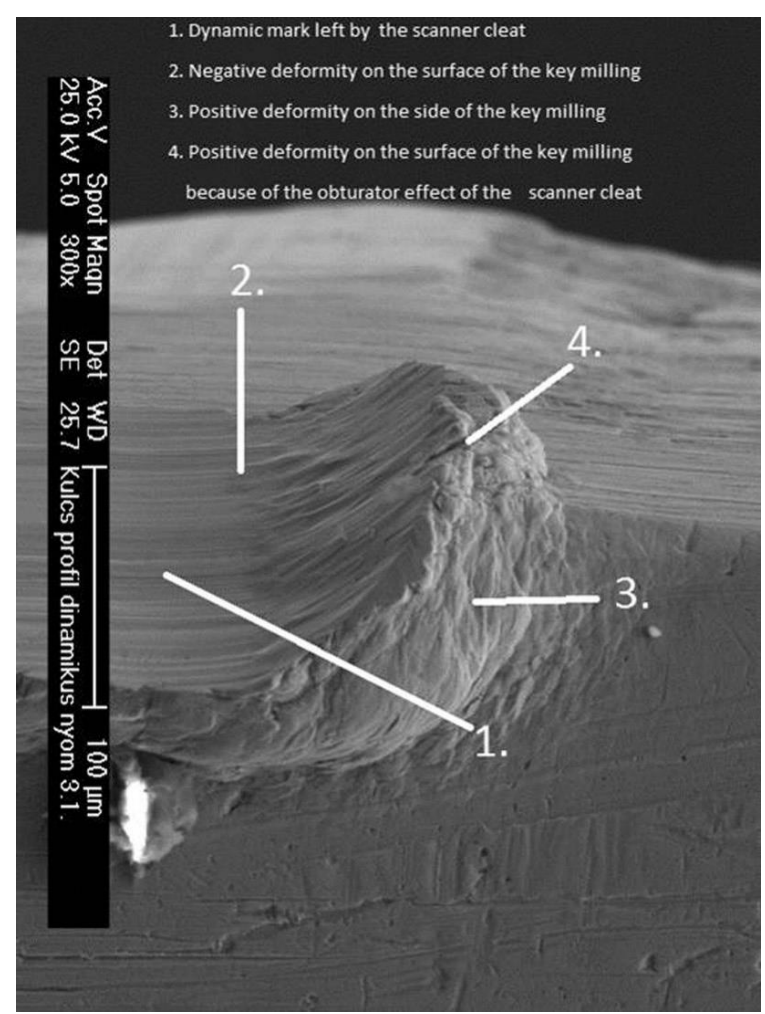

Figure 2. Scanning the cuts of an upwards milled traditional key with a key duplicator machine. The electron microscopic image of the depth guide in the final state of mark formation. (Source: Tóth Péter for HIFS physicist expert)

It is worthwhile to separate three relevant ranges of the scanner, because in regard to mark forming specialities those may be different. The first mark speciality is formed in the surroundings of the initial point, during which the static mark fragment of the depth guide remains. Even though this mark type is a small segment of the whole mark it still might serve added information sometimes for instance about the scanner stud's edge geometry and indi- vidual characteristics. The biggest scale scanning path belongs to the middle range, whilst the operational final state depth guide belongs to the third, and several deformities of key milling profile belonging to the latter. (Figure 3) These shape shifts may not be evaluated as individ- ual specialities but the usage shabbiness on distorted surfaces may provide information about the relative time of mark formation. 


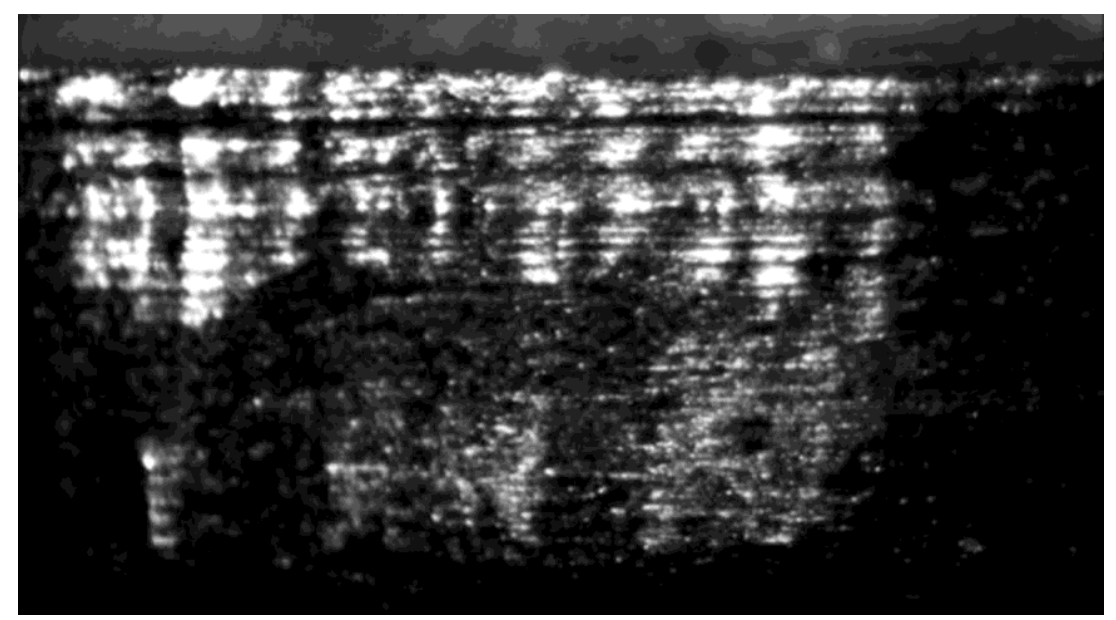

Figure 3. Microscopic top-view image part of a dynamic tool mark which was formed in the course of duplication sampling by a key duplicator machine's scanner on a traditional car key milling. (Source: own snapshot)

During sampling the key duplicator machine with depth guide may cause group distinc- tiveness level changes. One of these group specialities is that when in the mark the scanning angle or rather the range of the scanning angle may be mapped on the highest and the lowest steps of milling. Angle differences, are formed between the original top-view level and the scanned surface level, and represent well the key duplicator machine's structural perfor- mance, thereby giving details about the distance of the depth guide's suspensive tongue. (The operational edge angle of the scanner stud is denoted on Figure 2.) The depth guides' vertical course character is an arc in much of the key duplicator machines, and on condition that the key which is used for duplication sampling moves on a straight course during sampling and according to the heights of the milling steps the scanning cleat makes a different rotation, at particular parts of the mark it creates specific tracing. In case of traditionally formed grooves this tracing characteristic shows itself insomuch as on the horizontal parts of the groove steps it includes angle with the edges of the slant plane in alignment with the fore-axis. It is also the special mark formative feature of the depth guide that on the horizontal surface of the equal height cuts in the dynamic mark there are two similar groove structures mapped.

The side thickness of the rigger milled method produced cylinder lock key grooves is usu- ally between 1.5-2.0 mm, the length of the depth guide may be 5-10 times longer, therefore only a small section of the depth guide takes part in the interaction. Two statements might be taken on the basis of the mark's mapped dimension on the milling and general characteristic.

- It is ascertainable from the continuity and flatness of the mark that the scanning speed or rather the pressure by the scanner head was constant and this points to the fact that the mark was formed by an automatic machine (after the clamping of the key and the initiation of the duplicating process no human intervention happened).

- From the shortage of mark continuity and microscopic roughness it can be determined that the speed or rather pressure by the scanner head was varied, and this points to the fact that the mark originates from a manual (human meddling happened during the whole duplicating process) feeding key duplicator machine. 
There is a less known method to duplicate the traditional milling of a key by scanning, which differs from those described above because the milling's shape of the duplicative key is not taken by continuous tracking but by forming the milling dents singly. This method may be used typically with cylinder lock keys and in the aspect of mark formation means a significant difference as compared to traditional shape follower scanning because other than dents no other tool mark is formed and for these marks the static mark formation is typical.

Beside the traditional upwards milled and cut keys the so called side milled keys are also used and the milling course is formed differently. In case of car keys this side milled con- struction means a simple or double milling course and within this an inner or outer course formation. The sampling technology of duplication of the side milled keys is different than that of traditional keys, because in case of these types of keys the scanning is done by a steel tongue. Going along the milling course of the linear pit milling machine the steel tongue leaves dynamic tool marks.

In dimension and position, different marks may be formed depending on the geometric size of the scanner tongues, the clamping precision and the shape of the milling course of the key being duplicated, and the intensity of the interaction. Depending on that the side, the end surface or the sharp edge the connecting point, the following mark types are created.

\section{Dynamic Mark Formed on the Grooves of an Inner Course Key}

This mark type is usually formed when the end of the scanner stud does not reach the lower level of the groove's course. The relative offset of the scanning cleat in its sheer position and the irregularity of the milling surface may cause different intensities during the imaging of the mark and may cause the deformity of the profile. On the figure below there is an example of a dynamic depth guide tool mark, where the intensity of the mark is stronger far from the level and getting closer to the level it disappears. (Figure 4)

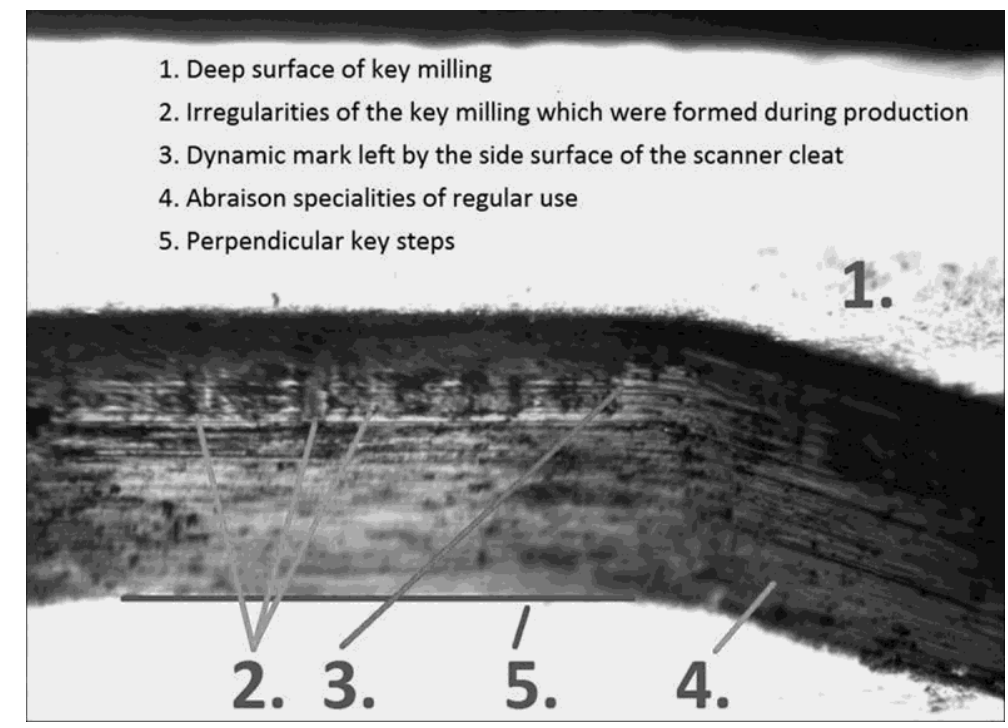

Figure 4. Microscopic image of the dynamic tool mark that was formed during the stud-scanning of a side cut inner course car key. (Source: own snapshot) 


\section{The Nascent Dynamic Mark on the Surface between the Steps of a Key}

On the deep surface of the milling, the mark of the scanner tongue is usually formed when it reaches the lower plain of the milling course. By such settings, usually only a small section of the scanner tongue takes part in mark formation. One of the mark's characteristics is the tracing course of the milling and the back and forth moving scanner tongue. (Figure 5)

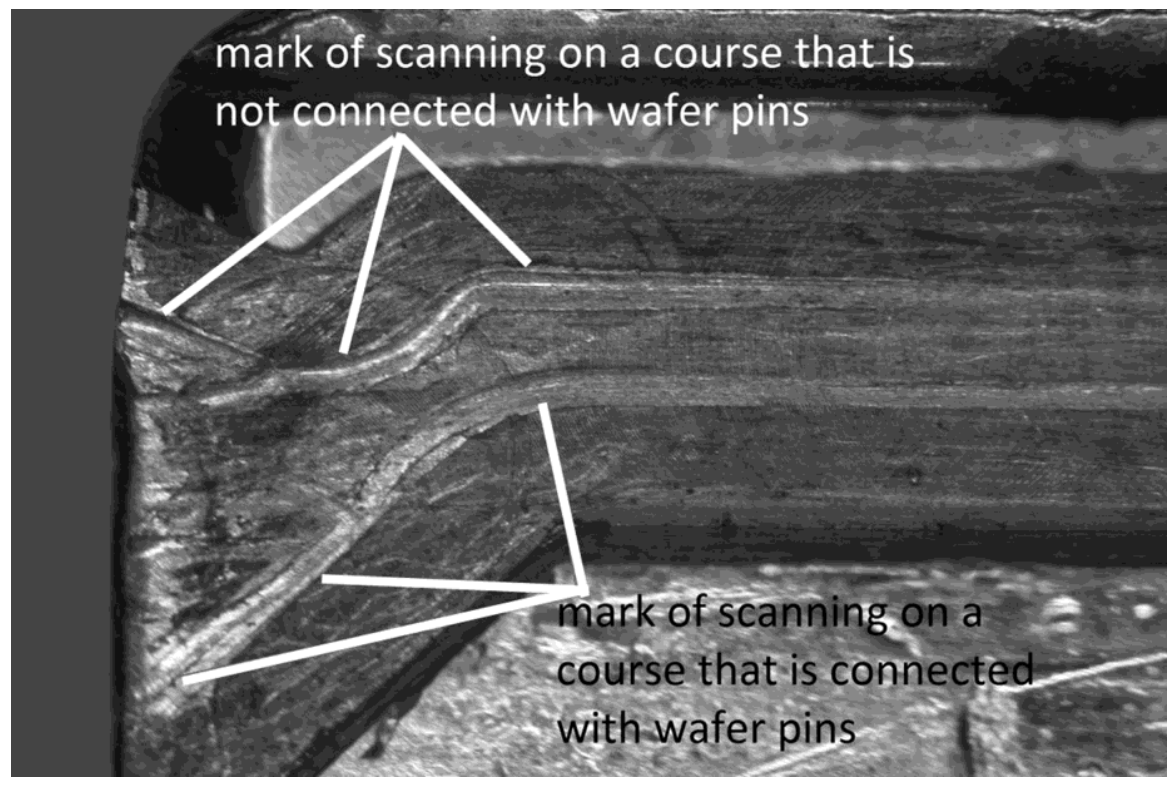

Figure 5. Part of an inner course car key milling about the surface between the milling courses. The dynamic mark of the key duplicator machine's scanner study. (Source: own snapshot)

\section{Nascent Mark on the Surface and on the Lower Collar of Groove Steps}

This mark type is mostly formed when there is a straight or an arched dip at the meeting-point of grooves and lower surface, and at the end of the scanner tongue there is no round-off or humbling and it is able to scan the cuts of the key deeply enough, e.g. certain BMW key types.

\section{Concludable Implications on the Basis of Dynamic Marks}

According to the common specialities of the dynamic mark, it is possible to deduce, what kind of course the marking equipment's scanner stud or cleat does during the mark formation process. The scanner head of the key duplication machine moves on such a forced course, whereby typical marks are left on the surface of the connecting grooves. This typical mark on the one hand reflects the individual characteristic of the scanner head, on the other hand serves information in reference to the construction of the key duplicator machine. These various mark specialities make it possible to differentiate the tool marks of scanning from any other mark types such as construction marks, different surface alterations of usage, spon- taneous impacts, and damages. 
By the combined comparative examination of general and over-shabbiness of the key under examination it is possible to deduct consequences about what scale the shabbiness of the key might have during sampling as well as what scale of usage shabbiness arose after scanning. On the basis of these comparisons it is possible to assume the development of the mark through the whole period of usage.

- The mark was issued on a spick-and-span key, and after the formation of the mark, the key was in use for a longer time. In this case the formation time of the mark is closer to the beginning of the given period.

- The mark was issued on a moderately used key, and after the formation of the mark, the key was in use for a longer time. This statement refers that the formation time of the inspected mark is estimated at the middle of the key's usage period.

- The mark was formed in the firmly worn-out state of the key and after its formation the key was in use for little time. This statement refers to the formation time of the inspected mark and is estimated at the middle of the key's usage period.

\section{The Formation of the Key's Shabbiness}

During adequate use the key goes through different mechanical effects which produce vari- ous featured changes on the surface of the key. Out of these, the most significant are the lock operation related alterations as long as the key is used regularly. The lock operating related changes are formed dependent upon the shaping and stock material of the key, elaboration of high standards, structure of the belonging lock, condition of structure elements, contami- nation and environmental conditions, typically in chafing characteristic, damage of galvani- zation coat, oxidation and in damaged lock part caused key damages format. Forensic tool mark examination shows those wearing specialities are more significant which are typically formed along a forced path and overlap the tangential surfaces of sampling. One of the most typical key indicators is the milling which frets distinctively because of the interconnection with the tumbler pin or wafer pin.

Fivaz and Zanetta carried out a model experiment with a vehicle key, and in the course of this they regularly used the key more than 3000 times. During their experiment they proved that the mark of the key duplicator machine's scanner may be detected even after numerous uses. [10] [11] By means of ordinary use this lock operating number signifies around one year of usage. [12]

\section{Mechanical Code, Individual Characteristic and Decoding of Vehicle Keys; Possibilities to Identify Vehicle Key and Vehicle}

The mechanical individual nature of vehicle keys is provided by the shape of the milling course and the related mechanical code. Within the mechanical code system the number of the tumbler parts and the number of the belonging mechanical code steps determine in what numeral conglomerate individual nature can be defined. For example, in case of an unsprang wafer, rotational bolting, six-wafer mechanical code system (e.g. Ford, Jaguar), 4 mechanical code steps belong to each wafer pin. This means that in case of six key (closing) pins the possibilities of theoretical variations is $4^{6}$ (4069). In practice this mechanical code variation is less since many wafer pin variations are not in use because of security aspects. On the basis 
of these a Ford or a Jaguar car key may be considered individual in a few thousand number of items conglomeration. Because of the repeat of mechanical codes more vehicles might have the same key code and milling.

In case of many vehicle types it is also possible to define the key and/or mechanical code by the chassis number. In case of several key types the key's keycode (number of key label) and the mechanical code which characterize the real shape of the milling, are the same. The so called Direct Code is used in several types of Ford, Jaguar and Renault for example. Since the mechanical code repeats, no vehicle identification code can be determined or rather can- not be restricted to one vehicle identifier. This does not mean that a vehicle key cannot be assigned to a vehicle thread-mark. Several manufacturers keep a record and on the basis of which by chassis number the key code and mechanical code can be identified and it is enough to presuppose by the mechanical code of the car key to be checked which vehicle it belongs to. Based on the above there is a possibility to identify the vehicle's authorised key code and the vehicle key's mechanical code.

It is important to note that an opening test during which the used key opens the lock(s) un- checked does not mean mechanical code identification of its own, that is to say it can happen when the lock cannot be opened by the same mechanical code dispose key even one adapted to the lock. Because of natural wearing and ageing it may happen that a differently milled key could be used as a proper key. (Table 1)

Table 1. Based on the above, abnormal effects may originate for the following reasons.

\begin{tabular}{|l|l|}
\hline $\begin{array}{l}\text { The structural change that caus- } \\
\text { es malfunction in key operation }\end{array}$ & The method of detecting abnormal occurrence \\
\hline $\begin{array}{l}\text { The usage shabbiness may reach } \\
\text { such a level when a key with dif- } \\
\text { ferent mechanical code instead of } \\
\text { the key with individual mechanical } \\
\text { code, can be used as a proper key. }\end{array}$ & $\begin{array}{l}\text { The presumption of the shabbiness level is possible } \\
\text { by the optical examination of the lock's part or by } \\
\text { endoscopic and borescopic examinations. }\end{array}$ \\
\hline $\begin{array}{l}\text { There was a mechanical code } \\
\text { modification earlier in the lock. }\end{array}$ & $\begin{array}{l}\text { Answering the question whether there was mechan- } \\
\text { ical code modification in a given lock mechanism, } \\
\text { is only possible after the collective examination of } \\
\text { ratchet elements and comparative examination of } \\
\text { shabbiness levels. }\end{array}$ \\
\hline Member & $\begin{array}{l}\text { Answering the question whether there is such a } \\
\text { structural element in the lock that by way of its } \\
\text { form-change and damage means obstruction in } \\
\text { point of adequate actuation of the lock can be ascer- } \\
\text { tained only by the examination of the inner structur- } \\
\text { al components. }\end{array}$ \\
\hline Presence of stock residue & $\begin{array}{l}\text { Answering the question whether there is such } \\
\text { strange residue or piece part in the lock that means } \\
\text { obstruction in point of adequate actuation of the } \\
\text { lock, can be ascertained only by the examination of } \\
\text { the inner structural components. }\end{array}$ \\
\hline
\end{tabular}



ratchet in the lock that means obstruction in point of adequate actuation of the lock, can be ascertained only by the examination of the inner structural components.

\section{Conclusion}

This essay introduced vehicle keys as forensically interpretable tool mark carriers. In the focus of different mark types the technological mark specialities, the emerged shabbiness during ordinary usage and the possible duplication sampling mark formations were dis- cussed. Beside the individual and group specialities the partial results of complex examinations may enlighten the "key" details of originality and vehicle usage, which may serve as ev- idence in the course of the criminal investigation. These details are carried by different mark specialties. The tool marks and other changes on the surface of the key may answer whether the examined vehicle key was part of the original key set, if there was any copy made, ma- nipulated, or the observable shabbiness was in accordance with the usage data of the vehicle. In addition, the individual identification of the key maker or the key duplicator machines are also possible by the comparative examination of the microscopic tool marks. The reader shall come to know various methods of inspection by the particular mark carrier of trasologycal marks, as well as the information content of marks and the deductible consequences of these.

\section{References}

[1] KATONA, G.: A nyomok azonositási vizsgálata a büntetőeljárásban. Budapest: Közgazdasági és Jogi Könyvkiadó, 1965.

[2] TREMMEL F., FENYVESI Cs.: Kriminalisztika tankönyv és atlasz. Budapest, Pécs: Dialóg Campus Kiadó, 2002.

[3] BÓCZ E.: Kriminalisztika. Budapest: BM Kiadó, 2004.

[4] LAKATOS J.: Kriminalisztikai alapismeretek. Budapest: Rendőrtiszti Főiskola, 2005. [5] FENYVESI Cs., HERKE

Cs., TREMMEL F.: Kriminalisztika - Tankönyv és Atlasz. Budapest, Pécs: Dialóg Campus Kiadó, 2005.

[6] TREMMEL F.: Bizonyitékok a büntetöeljárásban. Budapest, Pécs: Dialóg Kiadó, 2006. [7] FINSZTER G.: A

kriminalisztika elmélete és a praxis a büntetöeljárási reform tükrében. http://be.atw.hu/letoltes/Krimjegyzet.doc (downloaded: 2206 2015)

[8] STAUFFER, E., BONFANTI, M.: Forensic Investigation of Stolen-Recovered and Other Crime-Related Vehicles. Burlington, Oxford: Academic Press is an imprint of Elsevier, 2006. [9] KUMMER, S.,

BONFANTI, M., GALLUSSER, A.: I.e processus dc reproduction des clés et son intérêt en sciences forensiques (partie 2). Revue Internationale de Criminologie et de Police Technique et Scientifique, 512 (1998), 229-237.

[10] FIVAZ, E.: Etude des traces laissées par le processus de duplication des clés et leur persistance. Lausanne: Institut dc police scientifique et de criminologie. Université de Lausanne, 1997. 
ELEK Imre: Forensic Mark Examination of Vehicle Keys

[11] ZANETTA, S.: Duplication des clés à fraisage horizontal II. Etude d'éléments d'interprétation (persistance, traces d'usure) et de datation. Lausanne: Institut tie police scientifique et de criminologie. Université de Lausanne, 2001.

[12] HITZEMANN, M., KLEINHAUS, T.: Untersuchung von Fahrzeugschlüsseln. Aussagefähigkeit von Schlüsselbefunden für die Fallaufklärung Fahrzeugschlüsseln. Stuttgart: Dekra, 1995. 